\title{
Methane and Carbon Dioxide in Dual-Porosity Organic Matter: Molecular Simulations of Adsorption and Diffusion
}

\author{
Eliska Rezlerova ${ }^{1}$, John Brennan ${ }^{2}$, and Martin Lisal ${ }^{1}$ \\ ${ }^{1}$ Institute of Chemical Process Fundamentals Czech Academy of Sciences \\ ${ }^{2}$ US Army Research Laboratory Weapons and Materials Research Directorate
}

April 28, 2020

\begin{abstract}
The manuscript describes a computational study that provides molecular-level insight into shale gas adsorption and transport in shale rocks, which are composed of organic and inorganic matter. Atomistic simulations were used to generate realistic models of the organic matter structures with both micro- and mesoporosity, and correspond to mature and overmature type-II kerogens. These porous material models are unique to most other previous kerogen models since they contain other components (asphaltene/resin, hydrocarbons and carbon dioxide/water fractions) that are typically not modeled. The inclusion of these additional components significantly influences the resulting porous structure characteristics. The adsorption and diffusion behavior of methane (as a shale gas proxy) and methane/carbon dioxide mixtures were simulated in the model structures. Several key industrial-relevant findings are described in the manuscript.
\end{abstract}

\section{Hosted file}

TextFigures.pdf available at https : //authorea.com/users/309219/articles/440188-methane-and-carbondioxide-in-dual-porosity-organic-matter-molecular-simulations-of-adsorption-and-diffusion 